\title{
Association between HIV infection and hypertension: a global systematic review and meta-analysis of cross-sectional studies
}

Katherine Davis $^{1 *}$ (D), Pablo Perez-Guzman ${ }^{1}$, Annika Hoyer ${ }^{2}$, Ralph Brinks ${ }^{3}$, Edward Gregg ${ }^{4}$, Keri N. Althoff ${ }^{5}$, Amy C. Justice ${ }^{6}$, Peter Reiss ${ }^{7,8}$, Simon Gregson ${ }^{1,9}$ and Mikaela Smit ${ }^{1}$

\begin{abstract}
Background: Improved access to effective antiretroviral therapy has meant that people living with HIV (PLHIV) are surviving to older ages. However, PLHIV may be ageing differently to HIV-negative individuals, with dissimilar burdens of non-communicable diseases, such as hypertension. While some observational studies have reported a higher risk of prevalent hypertension among PLHIV compared to HIV-negative individuals, others have found a reduced burden. To clarify the relationship between HIV and hypertension, we identified observational studies and pooled their results to assess whether there is a difference in hypertension risk by HIV status.

Methods: We performed a global systematic review and meta-analysis of published cross-sectional studies that examined hypertension risk by HIV status among adults aged > 15 (PROSPERO: CRD42019151359). We searched MEDLINE, EMBASE, Global Health and Cochrane CENTRAL to August 23, 2020, and checked reference lists of included articles. Our main outcome was the risk ratio for prevalent hypertension in PLHIV compared to HIVnegative individuals. Summary estimates were pooled with a random effects model and meta-regression explored whether any difference was associated with study-level factors.

Results: Of 21,527 identified studies, 59 were eligible (11,101,581 participants). Crude global hypertension risk was lower among PLHIV than HIV-negative individuals (risk ratio 0.90, 95\% Cl 0.85-0.96), although heterogeneity between studies was high $\left(I^{2}=97 \%, p<0.0001\right)$. The relationship varied by continent, with risk higher among PLHIV in North America $(1.12,1.02-1.23)$ and lower among PLHIV in Africa $(0.75,0.68-0.83)$ and Asia $(0.77,0.63-0.95)$. Metaregression revealed strong evidence of a difference in risk ratios when comparing North American and European studies to African ones (North America 1.45, 1.21-1.74; Europe 1.20, 1.03-1.40).

Conclusions: Our findings suggest that the relationship between HIV status and prevalent hypertension differs by region. The results highlight the need to tailor hypertension prevention and care to local contexts and underscore the importance of rapidly optimising integration of services for HIV and hypertension in the worst affected regions. The role of different risk factors for hypertension in driving context-specific trends remains unclear, so development of further cohorts of PLHIV and HIV-negative controls focused on this would also be valuable.
\end{abstract}

Keywords: HIV, Hypertension, Blood pressure, Systematic review, Meta-analysis

\footnotetext{
* Correspondence: K.davis18@imperial.ac.uk

1 MRC Centre for Global Infectious Disease Analysis, Department of Infectious

Disease Epidemiology, St Mary's Campus, Imperial College London, London W2 1PG, UK

Full list of author information is available at the end of the article
}

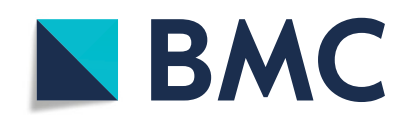

(c) The Author(s). 2021 Open Access This article is licensed under a Creative Commons Attribution 4.0 International License, which permits use, sharing, adaptation, distribution and reproduction in any medium or format, as long as you give appropriate credit to the original author(s) and the source, provide a link to the Creative Commons licence, and indicate if changes were made. The images or other third party material in this article are included in the article's Creative Commons licence, unless indicated otherwise in a credit line to the material. If material is not included in the article's Creative Commons licence and your intended use is not permitted by statutory regulation or exceeds the permitted use, you will need to obtain permission directly from the copyright holder. To view a copy of this licence, visit http://creativecommons.org/licenses/by/4.0/. The Creative Commons Public Domain Dedication waiver (http://creativecommons.org/publicdomain/zero/1.0/) applies to the data made available in this article, unless otherwise stated in a credit line to the data. 


\section{Introduction}

The introduction of antiretroviral therapy (ART) has had a substantial impact on the life expectancy of people living with HIV (PLHIV) [1]. As a result, PLHIV are increasingly ageing and affected by non-communicable diseases (NCDs), including hypertension [2]. Hypertension, though often asymptomatic, is a key risk factor for other NCDs, such as chronic kidney disease and cardiovascular disease [3], and can be controlled or uncontrolled in the presence of antihypertensives.

In recent years, a number of observational studies have found a differing prevalence of hypertension among PLHIV compared to HIV-negative individuals, with some finding an elevated burden $[4,5]$, and others finding a reduced burden [6,7]. Possible causes of elevated hypertension prevalence in PLHIV include chronic inflammation, increased microbial translocation and renal disease, blood vessel damage resulting from long-term ART exposure, and higher levels of behavioural risk factors among PLHIV in some communities $[8,9]$. Conversely, possible reasons for reduced hypertension burden among PLHIV include low blood pressure resulting from advanced HIV disease, better control of blood pressure due to additional healthcare support and lower levels of behavioural risk factors among PLHIV in some settings [7, 10, 11]. Limited comparability between PLHIV and HIV-negative controls in observational studies may also explain some of the differencing conclusions [12]. Despite the various plausible mechanisms and inconsistent evidence from observational research, no study to date has systematically established whether there is a global difference in hypertension by HIV status, nor its directionality. Such data will be vital to inform policy decisions on optimising hypertension prevention and care.

We aimed to perform a global systematic review and meta-analysis of cross-sectional studies to assess whether there is a difference in risk of prevalent hypertension by HIV status among adults aged over 15 . We also aimed to complete a meta-regression to explore whether any differences were associated with specific study-level factors.

\section{Methods}

\section{Search strategy and selection criteria}

We carried out a global systematic review and metaanalysis of cross-sectional studies to establish whether the risk of prevalent hypertension differs by HIV status, following the Preferred Reporting Items for Systematic Reviews and Meta-Analyses (PRISMA) guidelines [13]. We searched MEDLINE, EMBASE, Global Health and Cochrane CENTRAL Register of Controlled Trials from inception to August 23, 2020, using a structured search strategy to identify cross-sectional studies assessing the risk of prevalent hypertension in HIV-positive and HIV- negative individuals aged over 15. Searches were not restricted by language or quality of study, although unpublished reports and reports in conference abstracts were excluded to minimise the effect of selective reporting.

Full details on PRISMA compliance, inclusion criteria, search strategy, data collection and the process for contacting authors are in Additional file 1. Briefly, we included studies that used the following definitions for hypertension:

i) Blood pressure measurement thresholds equivalent to or higher than a systolic blood pressure (SBP) of $130 \mathrm{mmHg}$ or a diastolic blood pressure (DBP) of $80 \mathrm{mmHg}$ [14]

ii) Use of antihypertensive medication

iii) Electronic health record of a hypertension diagnosis

Studies investigating non-systemic hypertension (e.g. intracranial, pulmonary and portal hypertension) or that recruited or rejected people with conditions associated with hypertension (e.g., kidney disease, heart disease or diabetes mellitus) were excluded. In addition, studies of hospitalised populations or focusing solely on key populations (men who have sex with men, transgender people, commercial sex workers, people who inject drugs, prisoners and migrants) were excluded to reduce threats to external validity of the findings for the broader population of PLHIV.

After duplicate and retracted reports were removed, titles and abstracts were independently screened by KD and PPG, with conflicts resolved by MS. Full texts of remaining studies were assessed in the same way. Reference lists of included full-text articles were screened to identify additional studies. If several reports were identified that used the same study population, only the most recent or comprehensive study was included.

Three authors (KD, PPG and MS) independently extracted the data from studies, using a form which had been piloted on ten studies and refined accordingly. Summary estimates, rather than individual-level data, were extracted. Data extracted included first author, publication year, country of recruitment, study period, hypertension definition, sample size, age limits for inclusion, average participant age, gender distribution, percentage of PLHIV on ART and hypertension prevalence information. Data on hypertension prevalence included on number with hypertension and total number of people in each group, as well as reported or calculated standard error. Where relevant data was not available, corresponding authors were contacted.

\section{Data analysis}

Crude risk ratios (RRs) and 95\% confidence intervals (CIs) by HIV status were obtained from studies. 
Unadjusted estimates were used to aid comparability across studies. Where studies did not report RRs, they were calculated by dividing risk of prevalent hypertension among PLHIV by risk of prevalent hypertension among HIV-negative individuals (Eq. 1).

$\mathrm{RR}=\frac{\text { Risk of prevalent hypertension in PLHIV }}{\text { Risk of prevalent hypertension in HIV negative individuals }} 1$

95\% CIs were then calculated using the $\mathrm{R}$ package "meta" [15].

RRs were pooled with random effects models to adjust for variance within and between studies, using the Mantel-Haenszel method [16]. Statistical heterogeneity was assessed using the chi-squared test for heterogeneity on Cochran's $Q$ [17]. Heterogeneity was quantified using the $I^{2}$ statistic [18].

Sub-group analyses were performed to assess the impact of continent and hypertension definition on the pooled RR. The role of continent was examined because access to healthcare and characteristics of those at risk of, and living with, hypertension and HIV vary widely by region $[19,20]$. Hypertension definition was also examined as the various hypertension definitions may bias the $R R$ in different ways. For example, studies which defined hypertension via electronic health records may detect a relatively higher number of cases of hypertension in PLHIV because PLHIV have more contact with health services, so are more likely to have hypertension diagnoses added to their medical records.

Meta-regression was used to explore the contribution of continent, hypertension definition, mean age, the proportion of PLHIV on ART, the proportion of female participants and the year the study began, to the RR [21]. Variables used in the meta-regression were limited to those for which there was evidence of a plausible clinical or epidemiological effect and that were collected by enough studies to ensure statistical power [22-25]. Study data was examined to ensure the optimal choice of continuous or categorical coding. Several categories of hypertension definitions were combined for statistical power; "SBP $\geq 140 \mathrm{mmHg}$ or $\mathrm{DBP} \geq 90 \mathrm{mmHg}$ or use of antihypertensives", "SBP $\geq 140 \mathrm{mmHg}$ or $\mathrm{DBP} \geq 90 \mathrm{mmHg}$ " and "Use of antihypertensives" were coded as "Includes $\mathrm{SBP} \geq 140 \mathrm{mmHg}$ or $\mathrm{DBP} \geq 90 \mathrm{mmHg}$ or use of antihypertensives". Studies that defined hypertension using electronic health records were kept as a separate category. All further definitions were coded as "Other". The year a study began was coded as a categorical variable with two levels, "before 2005" and "2005 onwards", to reflect the increased availability of effective simplified and more tolerable ART regimens after 2005 [26].

Univariable associations between each variable and the $R R$ were examined. Those for which strong evidence of an effect was found in the univariable analysis $(p<0.05$ and clinically relevant effect size) were included in a multivariable meta-regression model. A permutation test was used to examine the robustness of meta-regression results [27].

The methodological quality, and comparability of PLHIV and HIV-negative individuals, recruited by included studies was assessed by two reviewers (KD and MS), using the National Heart, Lung and Blood Institute Study Quality Assessment Tools [28]. Any studies considered to be at high risk of bias were excluded from the quantitative analysis in a sensitivity analysis. Publication bias was evaluated by examining symmetry of contourenhanced funnel plots and using Egger's test, if there were more than ten studies in the funnel plot [29]. A pre-specified sensitivity analysis was performed, in which the Hartung-Knapp modification was applied to account for small sample sizes [30]. Further sensitivity analyses exploring the effect of using Joint United Nations Programme on HIV/AIDS ( UNAIDS) regions rather than continents for sub-group analyses were also carried out (Additional file 1).

Analyses were performed in $\mathrm{R}$ version 4.0.2, using the packages "meta" and "metafor" [15, 31].

The design and conduct of this review were specified in advance and documented in a protocol. Details were registered on PROSPERO (CRD42019151359, https:// www.crd.york.ac.uk/prospero/display_record. php?RecordID=151359).

\section{Results}

\section{Study selection and characteristics}

The database searches identified 21,523 records, with three more records identified through reference checking and one study recommended by a study author who was contacted for further information. After 6074 duplicate and retracted reports were removed, 15,449 remained, 334 of which were assessed in a full-text review. Of these, 59 were included in qualitative and quantitative syntheses (Fig. 1 and Additional file 1).

The studies had a combined total of 11,101,581 participants, with data collection occurring between 1985 and 2018 (Table 1). Most studies took place in Africa $(n=22 / 59,37.3 \%)$ and North America $(n=18 / 59$, 30.5\%), with two studies from Asia (3.3\%) (Fig. 2). The gender ratio among study participants varied substantially. Mean or median age across many studies fell between 30 and 50 years $(n=33 / 51,64.7 \%)$. Reassuringly, nearly all studies had age-matched controls, meaning that differences in hypertension prevalence are unlikely to be linked to age differences. In most studies, the majority of PLHIV were on ART ( $n=34 / 40,85 \%)$, and the most common hypertension definition was " $\mathrm{SBP} \geq 140 \mathrm{mmHg}, \mathrm{DBP} \geq 90 \mathrm{mmHg}$, or use of antihypertensives" ( $n=23 / 59,39.0 \%)$. 


\section{PRISMA Flow Diagram}

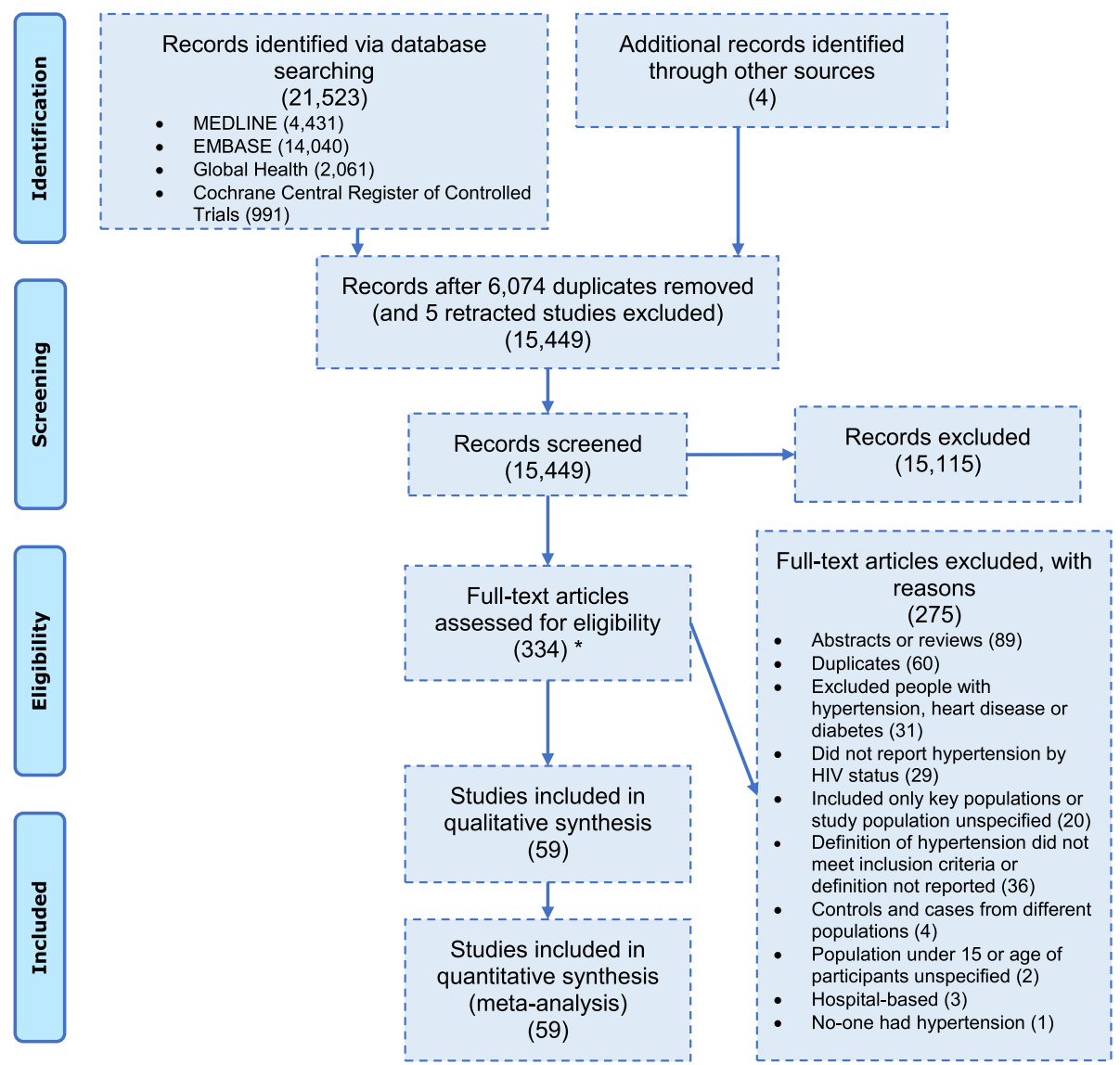

Fig. 1 PRISMA flow diagram of the study selection process. The asterick indicates that this is the number of records selected, based on title and abstract

\section{Synthesis and sensitivity analyses}

The overall risk of crude prevalent hypertension was lower among PLHIV than HIV-negative individuals $(\mathrm{RR}=0.90$, 95\% CI 0.85-0.96) (Fig. 3), although there was strong evidence of heterogeneity between studies $\left(I^{2}\right.$ 97\%, $p<0.0001$ ).

Analysis by continent revealed considerable differences $(p<0.0001)$, with a RR of 0.75 (95\% CI 0.68-0.83) for African studies and a RR of 0.77 (95\% CI 0.63-0.95) for Asian studies contrasting with a RR of 1.12 (95\% CI 1.021.23) for North American studies. We did not find evidence that the RR differed among European $(R R=0.91$, 95\% CI 0.81-1.02) or South American studies $(R R=0.85$, $0.72-1.01)$. Analysis also highlighted heterogeneity associated with the definition of hypertension ( $p=0.0001$, Additional file 1). Studies defining hypertension as "SBP $\geq 140 \mathrm{mmHg}$ or $\mathrm{DBP} \geq 90 \mathrm{mmHg}$ " $(\mathrm{RR}=0.75,0.66-$ $0.85)$, "Use of antihypertensives" ( $R R=0.63,0.41-0.96)$ or "SBP $\geq 160 \mathrm{mmHg}$ or $\mathrm{DBP} \geq 95 \mathrm{mmHg}$ " $(\mathrm{RR}=0.51,0.29$ 0.90) reported lower prevalence among PLHIV. By contrast, strong evidence for a difference was not established for any other hypertension definition sub-group.

In univariate meta-regression analyses, only continent and hypertension definition were predictors of the RR (Additional file 1). Multivariable meta-regression including these two predictors revealed that the effect of hypertension definition was lost after controlling for continent (Table 2). The meta-regression results provided strong evidence that the RR for hypertension by HIV status was higher in North America and Europe than Africa (North America RR $=1.45,95 \% \mathrm{CI}$ 1.21-1.74; Europe 1.20, 1.03-1.40). We did not find evidence of a difference when comparing Africa to the other continents (Table 2). A permutation test revealed results that were largely in line with the original model, suggesting that these findings are robust (Additional file 1).

Two studies were found to be at high risk of bias. They did not recruit all their subjects from similar populations, justify their sample size or apply inclusion and exclusion criteria uniformly (Additional file 1) [34, 36]. The remaining studies were of low or medium risk of 


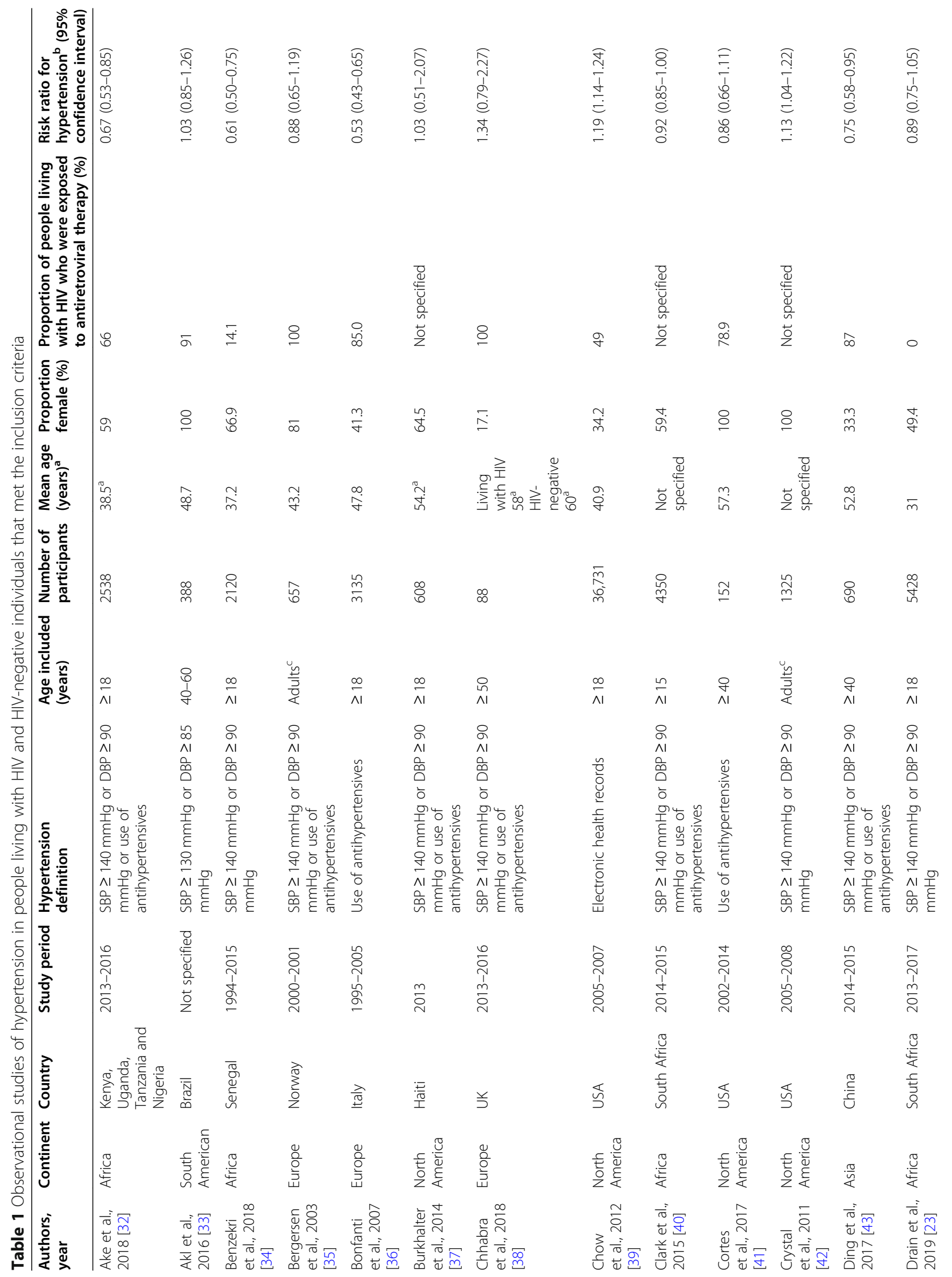




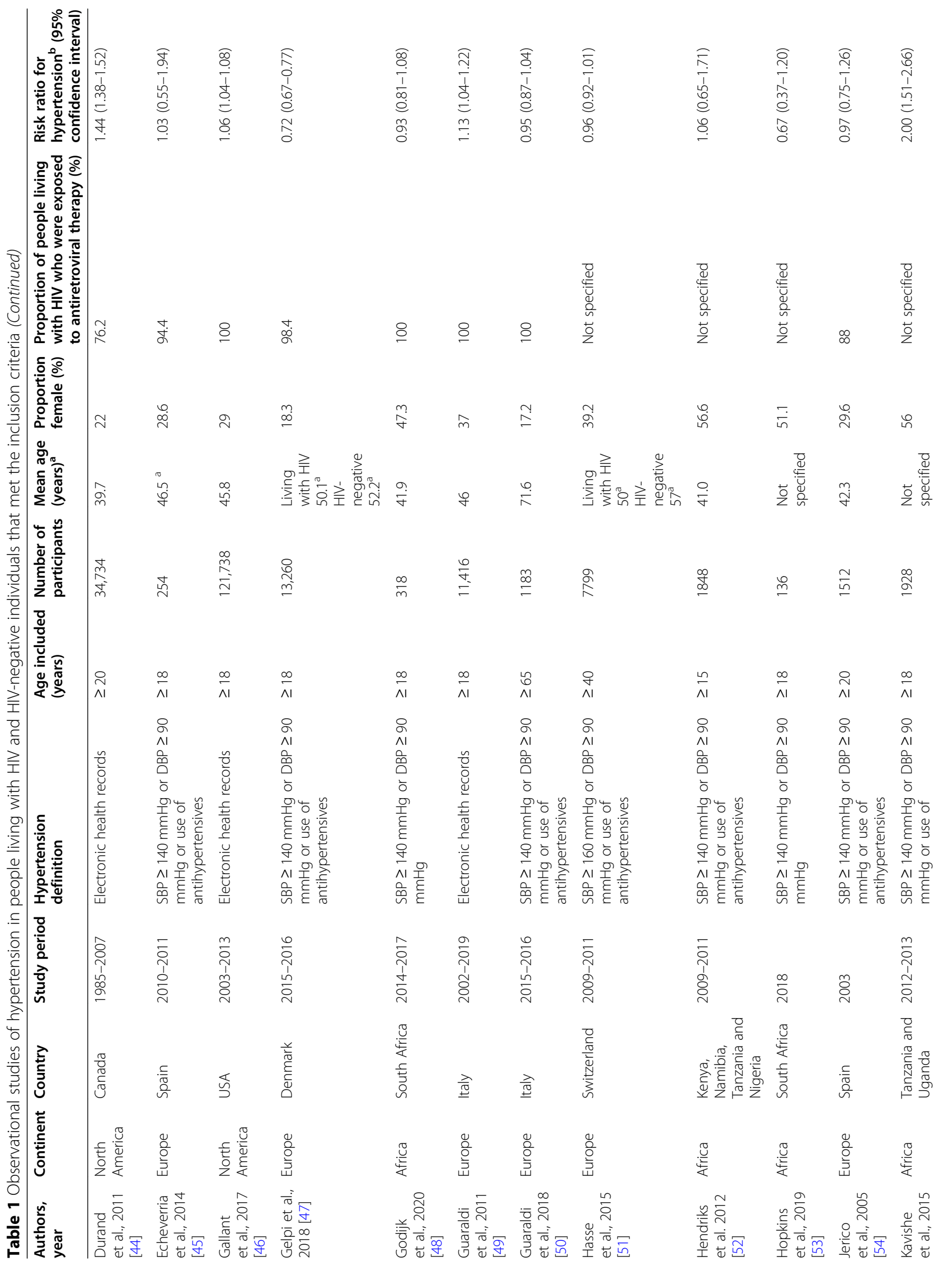


Davis et al. BMC Medicine

(2021) 19:105

Page 7 of 16

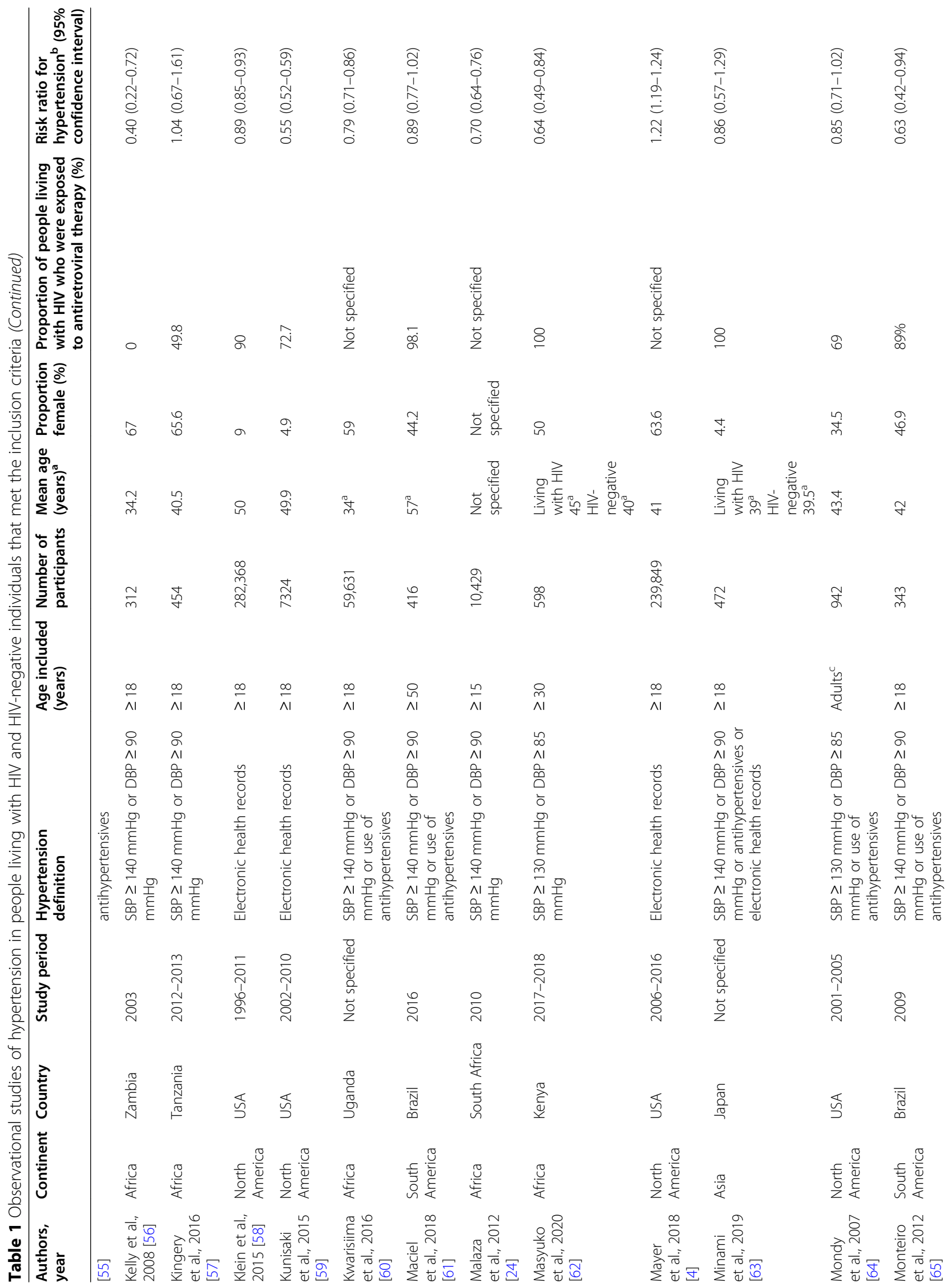


Davis et al. BMC Medicine $\quad$ (2021) 19:105

Page 8 of 16

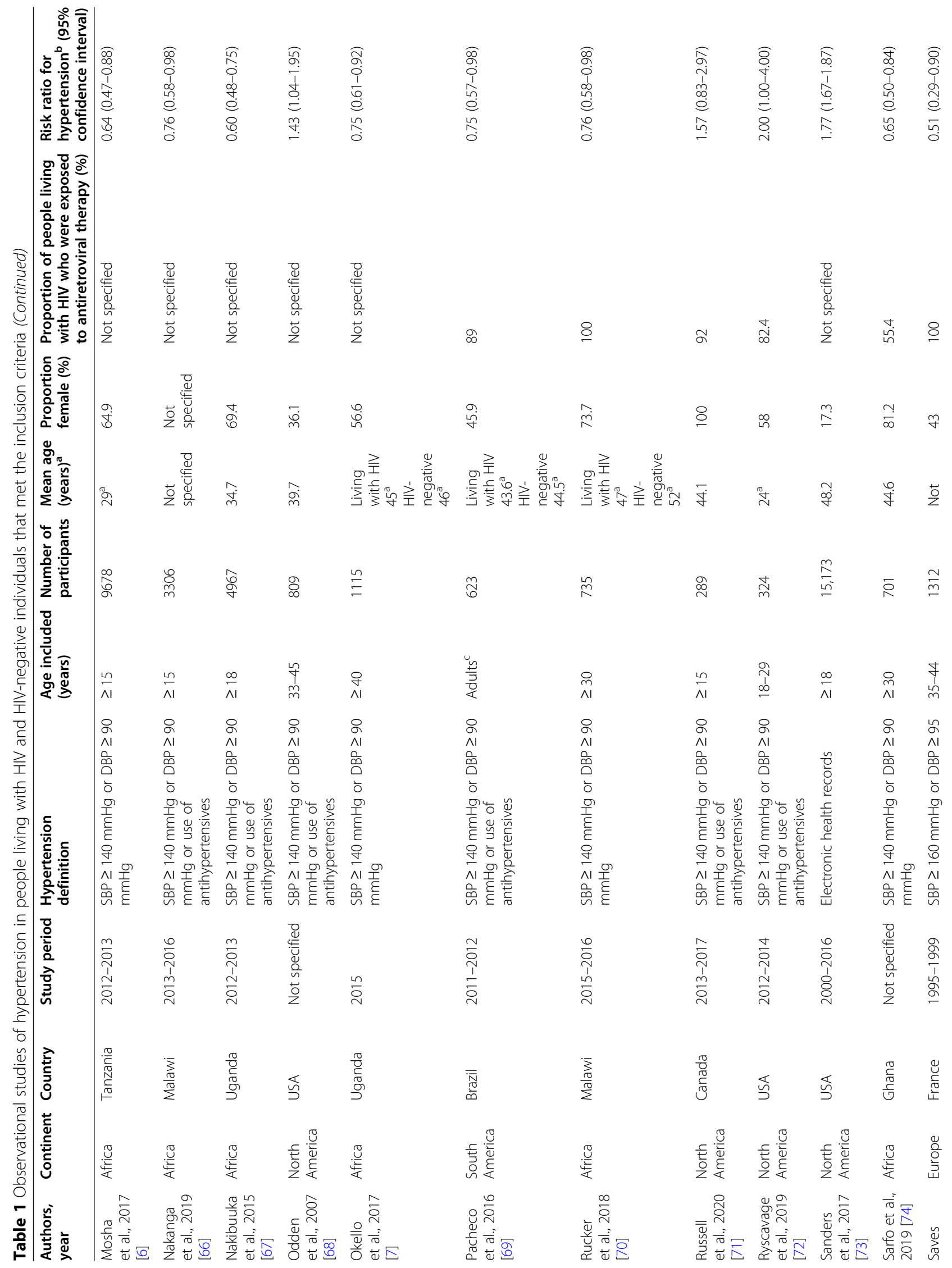




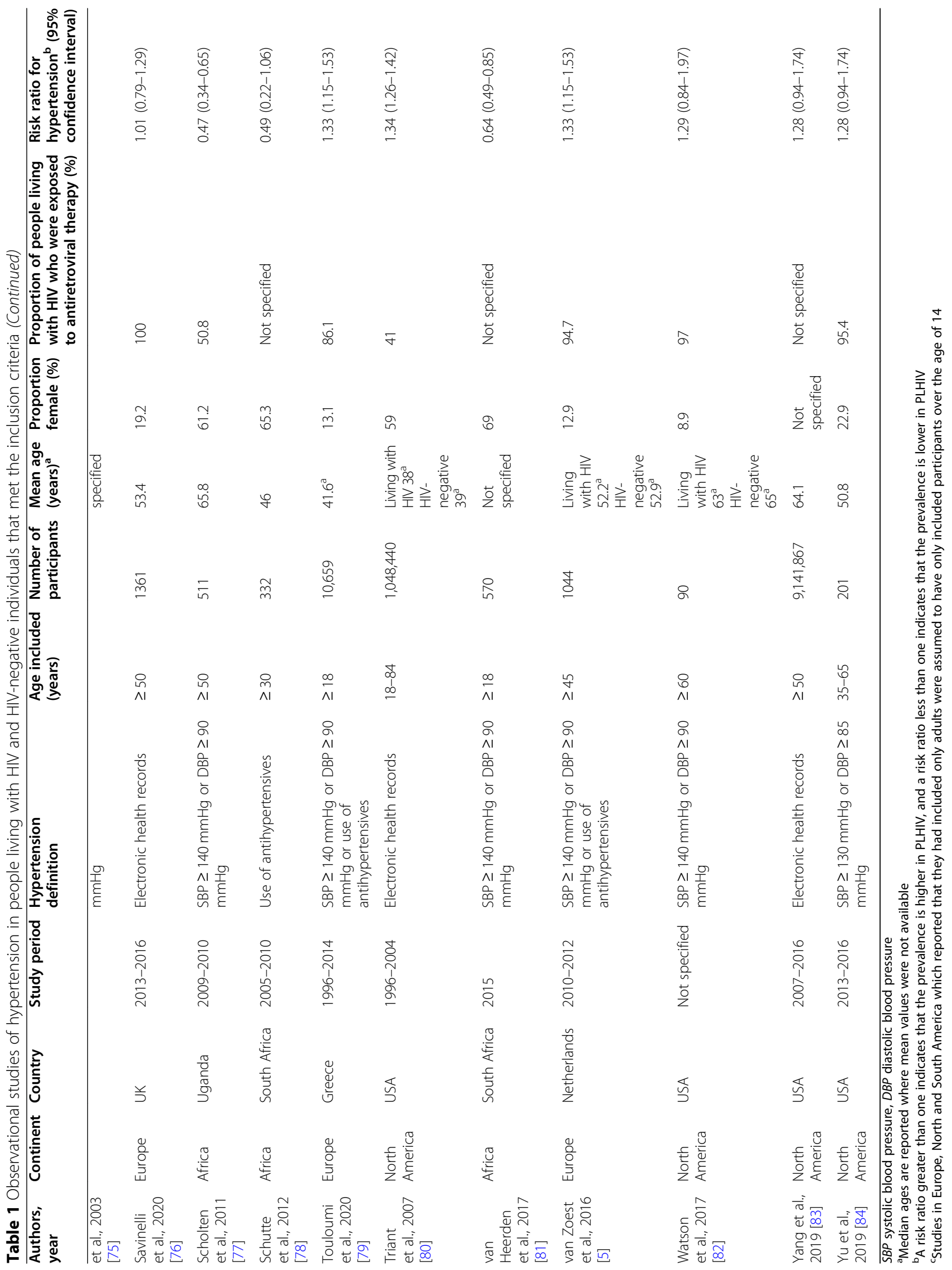




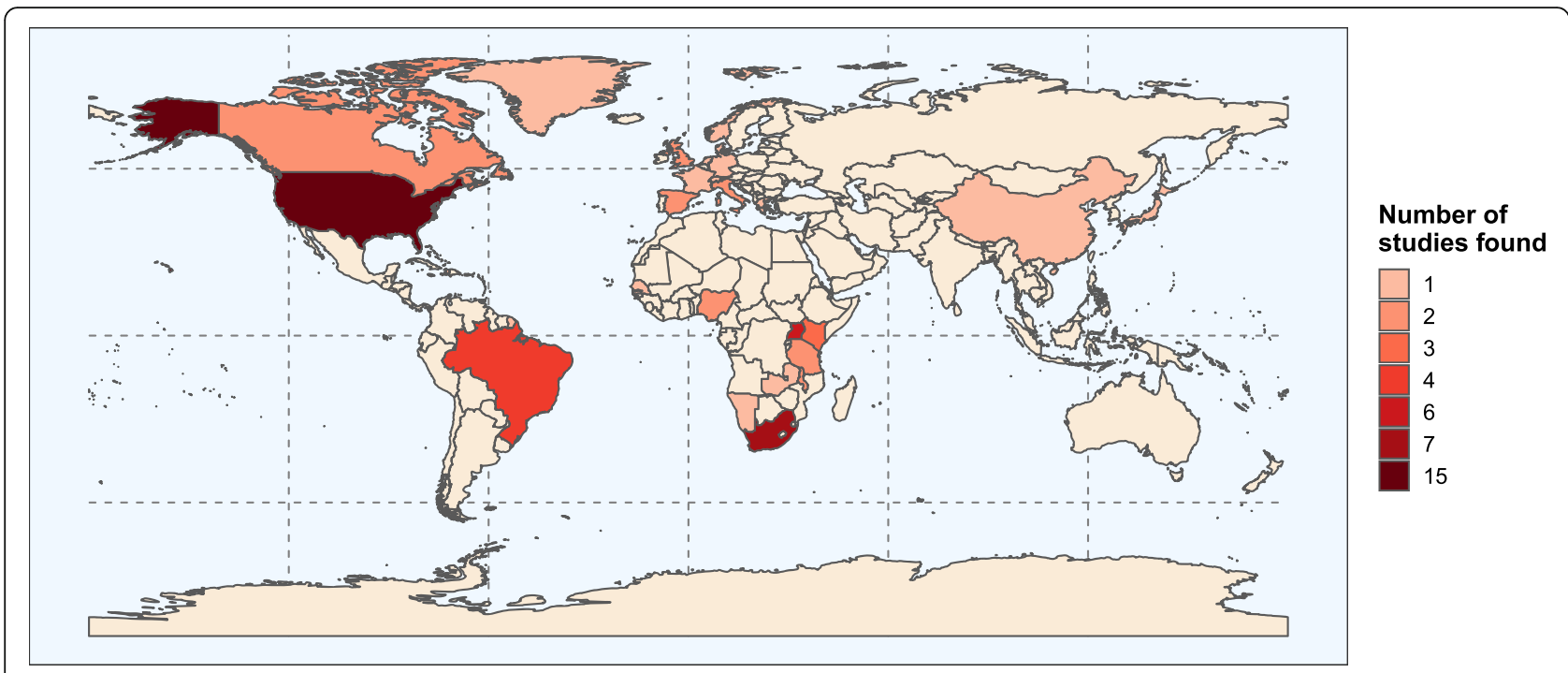

Fig. 2 Global distribution of sites used in included studies

bias. Removing the two studies at high risk of bias did not substantially alter our results (Additional file 1).

Visual inspection of a contour-enhanced funnel plot including all studies, and the use of Egger's test, revealed strong evidence of asymmetry $(p=0.049)$. While this may indicate publication bias, contour-enhanced funnel plots and Egger's tests for each continent did not reveal substantial asymmetry, suggesting the asymmetry in the overall plot is due to RR variation by location (Additional file 1). Sensitivity analyses using the HartungKnapp modification widened the confidence intervals around the overall pooled RR, although the evidence of a difference remained clear $(R R=0.90,0.83-0.98)$. Analysis by the UNAIDS region revealed results which corroborated findings by continent. For example, hypertension risk was lower among PLHIV for studies in East and Southern Africa ( $R R=0.76,0.68-0.86)$, West and Central Africa (0.63, 0.54-0.74) and Asia and the Pacific $(0.77,0.63-0.95)$. Full details on sensitivity analyses are in Additional file 1.

\section{Discussion}

\section{Summary of evidence}

To our knowledge, this is the first global systematic review and meta-analysis to compare the risk of prevalent hypertension among PLHIV and HIV-negative individuals. We found that the overall global crude risk of prevalent hypertension was lower among PLHIV than HIV-negative individuals. However, there was a high degree of heterogeneity between studies. Sub-group analyses revealed that the relationship varied greatly by region, with risk higher among PLHIV in North America and lower among PLHIV in Africa and Asia. Meta-regression confirmed this, providing strong evidence of a difference in the pooled RR between
North American studies and African studies, and between European studies and African studies.

\section{Evidence in context}

Our findings are in line with previous studies, which have contrasted global estimates without ensuring comparability between populations. A 2017 systematic review estimating the global prevalence of hypertension among PLHIV reported that approximately $25 \%$ of PLHIV had hypertension; when the authors compared their prevalence with a separate global prevalence estimate for the general population, they found that their result from PLHIV was lower [85]. A second recent review on the same topic found a similar prevalence estimate for PLHIV [86]. Our results by continent are also consistent with regional systematic review data [10, 86, 87]. For example, Dillon et al. performed a systematic review of blood pressure by HIV status in sub-Saharan Africa and found that HIV infection was associated with lower DBP and SBP [10]. Similarly, Bigna et al. carried out a systematic review on risk of prevalent hypertension, which focused only on PLHIV, and reported a higher risk of prevalent hypertension in North America and Western and Central Europe compared with other regions [86]. Unlike these existing studies, our analysis was global and only included studies that directly compared the risk of prevalent hypertension between PLHIV and HIV-negative individuals living in the same communities.

Our results also have important policy implications for the management of hypertension and HIV. They highlight the need for health systems globally to provide effective prevention and care for hypertension, to mitigate downstream health impacts including cardiovascular and renal complications [3]. Yet, several 


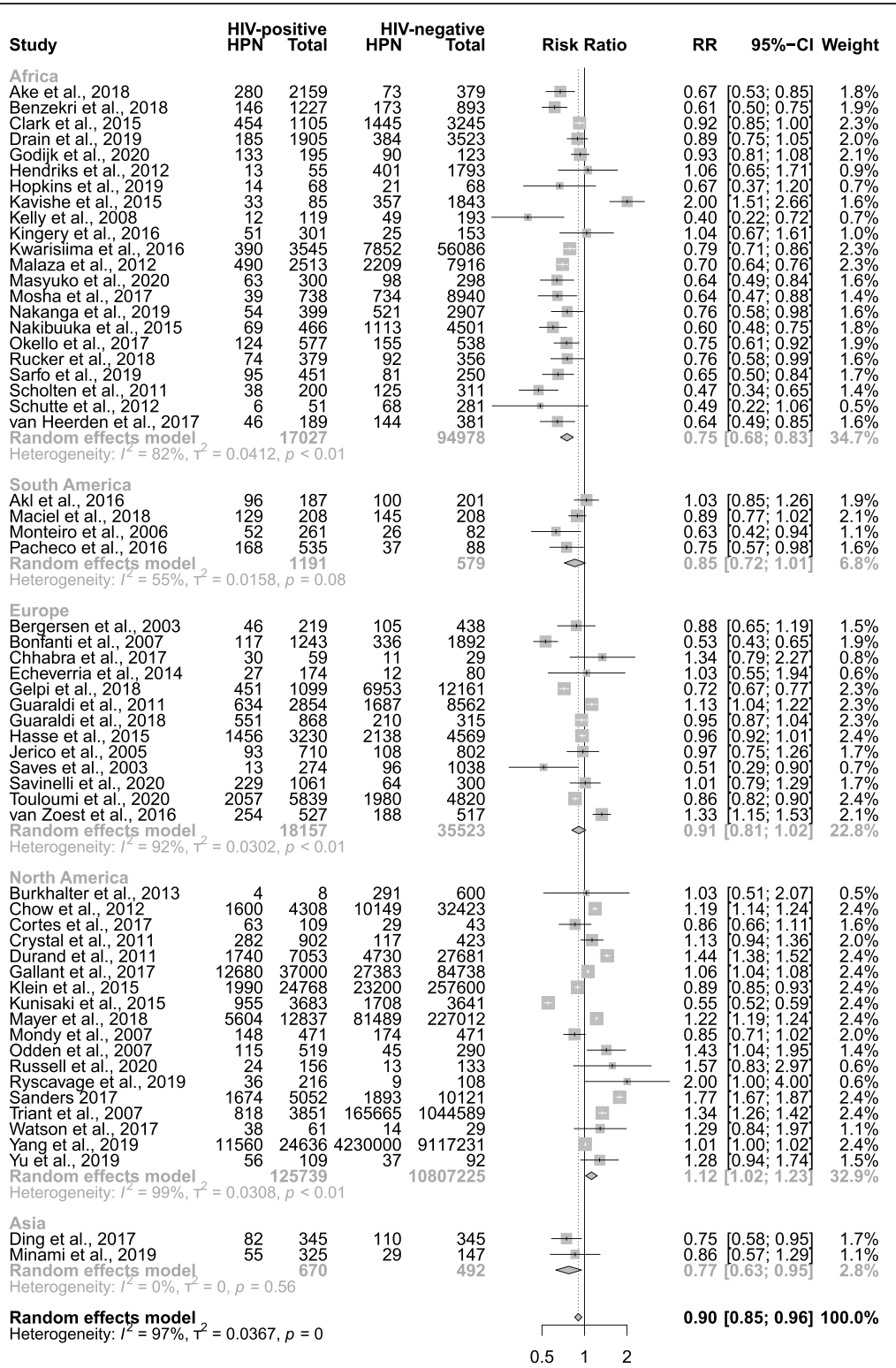

Fig. 3 Forest plot of the risk ratio for hypertension by HIV status, categorised by continent. Values less than one indicate a lower hypertension prevalence in people living with HIV. Estimates were pooled using a random effects model, with a $p$-value for sub-group differences less than 0.0001. RR risk ratio, Cl confidence interval

studies have demonstrated important gaps in the treatment cascade, with a large proportion of patients either undiagnosed, untreated or with uncontrolled hypertension $[88,89]$.

Various strategies could be employed by clinicians and policymakers to overcome these challenges for both PLHIV and HIV-negative individuals, with our results suggesting that a tailored, regional approach is required. In areas where the risk of prevalent hypertension is higher among PLHIV, optimising integration of hypertension services into HIV care by capitalising on pre-existing systems and multidisciplinary approaches will be key [90]. Where the risk of prevalent hypertension is lower in PLHIV, it will be essential to consider trade-offs between delivering HIV-specific integrated interventions and population-level approaches for hypertension. Limited resources for integration need to be focused on the diseases with both the largest overlapping burdens with HIV and the most costeffective strategies to diagnose and treat this dual burden, to ensure the greatest benefit for patients and health systems [90]. It is also important to recognise that geographic patterns in the relationship between HIV and hypertension may shift over time as patterns of ART exposure, severe disease in PLHIV and access to healthcare change; 
Table 2 Multivariable meta-regression $\left(R^{2}=13.88 \%\right)$

\begin{tabular}{|c|c|c|c|c|c|}
\hline & $\begin{array}{l}\text { Number of } \\
\text { studies }\end{array}$ & $\begin{array}{l}\text { Number of } \\
\text { participants }\end{array}$ & $\begin{array}{l}\text { Risk ratio ( } 95 \% \\
\text { confidence interval) }\end{array}$ & $\begin{array}{l}p \text {-value for } \\
\text { sub-category }\end{array}$ & $\begin{array}{l}\text { Overall } \\
p \text {-value }\end{array}$ \\
\hline Hypertension definition & & & & & 0.002 \\
\hline $\begin{array}{l}\text { Includes systolic blood pressure } \geq 140 \mathrm{mmHg} \text { or diastolic } \\
\text { blood pressure } \geq 90 \mathrm{mmHg} \text { and/or use of antihypertensives }\end{array}$ & 41 & 148,868 & 1 & - & \\
\hline Electronic health records & 11 & $10,941,001$ & $1.04(0.87-1.24)$ & 0.643 & \\
\hline Other & 7 & 11,712 & $0.97(0.80-1.17)$ & 0.748 & \\
\hline Continent & & & & & 0.657 \\
\hline Africa & 22 & 112,005 & 1 & - & \\
\hline Asia & 2 & 1162 & $1.06(0.74-1.50)$ & 0.763 & \\
\hline Europe & 13 & 53,680 & $1.20(1.03-1.40)$ & 0.019 & \\
\hline North America & 18 & $10,932,964$ & $1.45(1.21-1.74)$ & $<0.001$ & \\
\hline South America & 4 & 1770 & $1.13(0.89-1.43)$ & 0.327 & \\
\hline
\end{tabular}

further research focused on trends over time will provide additional insight for policymakers into the extent of these alterations and how they can be managed. Whatever the specific strategies and policies employed, our results highlight the need for locally focused, resilient and adaptable healthcare to respond to the varying challenges posed by hypertension and HIV.

Key to tailored care will be a better understanding of why the burden of hypertension by HIV status may differ by region. One possible hypothesis is that PLHIV in Africa and Asia are more likely to experience advanced HIV disease leading to lower blood pressure [7]. Differences between regions in patterns of previous experiences of ART before the study, which would not have been captured by our measure of ART usage during a study, may also play a role [25]. In addition, patterns of behavioural risk factors and experience of hypertension care by HIV status in a region may influence hypertension prevalence $[10,11]$. For example, PLHIV on ART may be more likely to have received healthcare services for hypertension as a result of regular visits to clinics [91]. To clarify the health trajectory and mechanisms involved in NCD development among ageing PLHIV, there has been a push to set-up cohorts of PLHIV and appropriate HIV-negative controls, such as the American Veterans Ageing Cohort Study and Dutch $\mathrm{AGE}_{\mathrm{H}} \mathrm{IV}$ Cohort [12]. Our study highlights the importance of these cohorts and the need for additional African and Asian cohorts, which could further clarify setting-specific risk factors by HIV status. Pre-existing cohorts in these settings, such as those run by the Network for Analysing Longitudinal Population-based HIV/AIDS data on Africa (ALPHA network), the African Non-Communicable Disease Longitudinal data Alliance (ANDLA) and Health and Aging in Africa: A Longitudinal Study of an INDE
PTH Community in South Africa (HAALSI) can offer insights into the relationships between HIV and hypertension [92, 93]. However, focused, specific cohort studies will ensure that highly comparable controls are recruited and detailed relevant data, including information on diet, exercise and inflammatory markers are gathered. This will allow mechanisms which may underly regional differences in hypertension prevalence to be more precisely identified.

\section{Strengths and limitations}

Our study has several strengths. It is the first global systematic review and meta-analysis to compare the risk of prevalent hypertension among PLHIV and HIV-negative individuals, revealing new insights that may influence hypertension care in coming years. By complementing the systematic review and meta-analysis with in-depth meta-regression and sensitivity analyses, the study was able to determine factors associated with differences in hypertension by HIV status. Many included studies focused on selecting comparable HIV-negative controls, providing robust RR estimates.

However, this review also has some limitations. First, there is heterogeneity in both the populations investigated and the hypertension measurement procedures across the studies. Second, the quality of included studies varied substantially, although only two were found to be at high risk of bias. Third, there was large heterogeneity in the type of additional data collected by studies and the number of studies from each region, which meant that we were unable to examine all factors associated with hypertension, such as body mass index and physical activity levels, in our meta-regression or to fully explore the relationship in Asia [94]. HIV-related information, including patterns of exposure to ART prior to the study, viral suppression statistics and CD4 counts, 
was also rare. The lack of data makes it hard to pinpoint why the differences we report in hypertension prevalence by HIV status occurred. Moreover, few included studies (approximately 12) provided any adjusted estimates for risk of prevalent hypertension by HIV status; this was mainly because the focus of the paper was on a different, but related objective. When studies did provide adjusted estimates, the variables which were selected for adjustment differed considerably. It was, therefore, not possible to perform a comprehensive analysis of adjusted estimates. Further studies with a more systematic approach to collecting data on hypertension risk factors will allow more detailed analysis.

\section{Conclusions}

This study suggests that the relationship between HIV status and risk of prevalent hypertension differs by region. The results emphasise the need for hypertension prevention and care to be tailored to the local epidemiological context and for further cohorts of PLHIV and HIV-negative controls to ascertain mechanisms driving these context-specific trends.

\section{Abbreviations}

ANDLA: African Non-Communicable Disease Longitudinal data Alliance; ALPHA: Analysing Longitudinal Population-based HIV/AIDS data on Africa; ART: Antiretroviral therapy; Cl: Confidence interval; DBP: Diastolic blood pressure; HAALSI: Health and Aging in Africa: A Longitudinal Study of an INDE PTH Community in South Africa; NCD: Non-communicable disease; PRISMA: Preferred Reporting Items for Systematic Reviews and Meta-Analyses; PLHIV: People living with HIV; RR: Risk ratio; SBP: Systolic blood pressure; UNAIDS: Joint United Nations Programme on HIV/AIDS

\section{Supplementary Information}

Supplementary information accompanies this paper at https://doi.org/10. 1186/s12916-021-01978-7.

Additional file 1. Supplementary material. Combined supporting information. This file contains the PRISMA checklist, further details on the search process and additional results.

\section{Acknowledgements}

The authors wish to thank the researchers who replied to requests for information, including but not limited to Brian Houle, Carla Fourie, Chris Longenecker, Giuseppe De Socio, Joel Gallant, Noelle Benzekri, Partho Sengupta, Paul Kelly, Robert Kalyesubula, Xavier Gomez-Olive, Jaya George, Melanie Murray, Wisdom Nakanga, Furahini Tluway, Sanne Møller, Noor Godijk and Michele Ramsay (on behalf of the H3Africa AWI-Gen study).

\section{Authors' contributions}

MS, SG, EG and KD conceived the study and developed the methods. KD, MS and PPG developed the search strategy, which KD implemented. KD, MS and PPG screened the abstracts and extracted the data, and KD and MS assessed the quality of each record included. KD performed the analysis and generated figures and estimates, with the methodological support of RB and $A H$. EG, SG, PR, AJ and KA contributed to the positioning of the results and care implications. KD led the writing of the manuscript with MS, and all authors commented on and contributed to the finalisation of the manuscript. The authors read and approved the final manuscript.

\section{Funding}

This work was supported by the Wellcome Trust [220098/Z/20/Z to KD]; the Civilian Research and Development Foundation Global (prime is President's Emergency Plan for AIDS Relief) [OISE-9531011 to MS and PPG]; the National Institutes of Health [1R21AG053093-01 to MS and PPG] and the Medical Research Council Centre for Global Infectious Disease Analysis [MR/R015600/ 1 to KD, PPG, SG and MS], which is jointly funded by the UK Medical Research Council and Foreign, Commonwealth \& Development Office. The funding bodies had no role in the design of the study and collection, analysis and interpretation of data or in writing the manuscript.

\section{Availability of data and materials}

All data generated or analysed during this study are included in this published article and its supplementary information files.

\section{Declarations}

Ethics approval and consent to participate

Not applicable.

\section{Consent for publication}

Not applicable.

\section{Competing interests}

The authors declare that they have no competing interests.

\section{Author details}

${ }^{1}$ MRC Centre for Global Infectious Disease Analysis, Department of Infectious Disease Epidemiology, St Mary's Campus, Imperial College London, London W2 1PG, UK. ²Department of Statistics, Ludwig-Maximilians-University Munich, Munich, Germany. ${ }^{3}$ Hiller Research Unit of Rheumatology, University Hospital Duesseldorf, Duesseldorf, Germany. ${ }^{4}$ Department of Epidemiology and Biostatistics, Imperial College London, London, UK. ${ }^{5}$ Department of Epidemiology, Johns Hopkins University, Baltimore, MD, USA. ${ }^{6}$ Schools of Medicine and Public Health, Yale University, New Haven, CT, USA.

${ }^{7}$ Department of Global Health, Amsterdam University Medical Centers, University of Amsterdam and Amsterdam Institute for Global Health and Development, Amsterdam, Netherlands. ${ }^{8} \mathrm{HIV}$ Monitoring Foundation, Amsterdam, Netherlands. 'Biomedical Research and Training Institute, Harare, Zimbabwe.

Received: 12 January 2021 Accepted: 31 March 2021

Published online: 13 May 2021

\section{References}

1. Marcus JL, Leyden WA, Alexeeff SE, Anderson AN, Hechter RC, Hu H, Lam JO, Towner WJ, Yuan Q, Horberg MA, Silverberg MJ. Comparison of overall and comorbidity-free life expectancy between insured adults with and without HIV infection, 2000-2016. JAMA Netw Open. 2020;3(6):e207954. https://doi.org/10.1001/jamanetworkopen.2020.7954.

2. Smit M, Brinkman K, Geerlings S, Smit C, Thyagarajan $K$, van Sighem AV, et al. Future challenges for clinical care of an ageing population infected with HIV: a modelling study. Lancet Infect Dis. 2015;15(7):810-8. https://doi. org/10.1016/S1473-3099(15)00056-0.

3. Oparil S, Acelajado MC, Bakris GL, Berlowitz DR, Cífková R, Dominiczak AF, Grassi G, Jordan J, Poulter NR, Rodgers A, Whelton PK. Hypertension. Nat Rev Dis Prim. 2018;4(1):18014. https://doi.org/10.1038/nrdp.2018.14.

4. Mayer KH, Loo S, Crawford PM, Crane HM, Leo M, DenOuden P, Houlberg M, Schmidt M, Quach T, Ruhs S, Vandermeer M, Grasso C, McBurnie MA. Excess clinical comorbidity among HIV-infected patients accessing primary care in US community health centers. Public Health Rep. 2018;133(1):10918. https://doi.org/10.1177/0033354917748670.

5. van Zoest RA, Wit FW, Kooij KW, van der Valk M, Schouten J, Kootstra NA, Wiersinga WJ, Prins M, van den Born B, Reiss P, AGEhIV Cohort Study Group. Higher prevalence of hypertension in HIV-1-infected patients on combination antiretroviral therapy is associated with changes in body composition and prior Stavudine exposure. Clin Infect Dis. 2016;63(2):20513. https://doi.org/10.1093/cid/ciw285.

6. Mosha NR, Mahande M, Juma A, Mboya I, Peck R, Urassa M, Michael D, Todd J. Prevalence, awareness and factors associated with hypertension in 
North West Tanzania. Glob Health Action. 2017;10(1):1321279. https://doi. org/10.1080/16549716.2017.1321279.

7. Okello S, Ueda P, Kanyesigye M, Byaruhanga E, Kiyimba A, Amanyire G, Kintu A, Fawzi WW, Muyindike WR, Danaei G. Association between HIV and blood pressure in adults and role of body weight as a mediator: cross-sectional study in Uganda. J Clin Hypertens. 2017;19(11):1181-91. https://doi.org/1 $0.1111 /$ jch. 13092.

8. van Zoest RA, van den Born B-JH, Reiss P. Hypertension in people living with HIV. Curr Opin HIV AIDS. 2017;12(6):513-22. https://doi.org/10.1097/ COH.0000000000000406.

9. Fahme SA, Bloomfield GS, Peck R. Hypertension in HIV-infected adults: novel pathophysiologic mechanisms. Hypertension. 2018;72(1):44-55. https://doi. org/10.1161/HYPERTENSIONAHA.118.10893.

10. Dillon DG, Gurdasani D, Riha J, Ekoru K, Asiki G, Mayanja BN, Levitt NS, Crowther NJ, Nyirenda M, Njelekela M, Ramaiya K, Nyan O, Adewole OO, Anastos K, Azzoni L, Boom WH, Compostella C, Dave JA, Dawood H, Erikstrup C, Fourie CM, Friis $\mathrm{H}$, Kruger A, Idoko JA, Longenecker CT, Mbondi S, Mukaya JE, Mutimura E, Ndhlovu CE, Praygod G, Pefura Yone EW, Pujades-Rodriguez M, Range N, Sani MU, Schutte AE, Sliwa K, Tien PC, Vorster EH, Walsh C, Zinyama R, Mashili F, Sobngwi E, Adebamowo C, Kamali A, Seeley J, Young EH, Smeeth L, Motala AA, Kaleebu P, Sandhu MS, African Partnership for Chronic Disease Research (APCDR). Association of HIV and ART with cardiometabolic traits in sub-Saharan Africa: a systematic review and meta-analysis. Int J Epidemiol. 2013;42(6):1754-71. https://doi. org/10.1093/ije/dyt198.

11. Kwarisiima D, Atukunda M, Owaraganise A, Chamie G, Clark T, Kabami J, Jain V, Byonanebye D, Mwangwa F, Balzer LB, Charlebois E, Kamya MR, Petersen M, Havlir DV, Brown LB. Hypertension control in integrated HIV and chronic disease clinics in Uganda in the SEARCH study. BMC Public Health. 2019; 19(1):511. https://doi.org/10.1186/s12889-019-6838-6.

12. Sabin CA, Reiss P. Epidemiology of ageing with HIV. AIDS. 2017; 31(Supplement 2):S121-8. https://doi.org/10.1097/QAD.0000000000001374

13. Liberati A, Altman DG, Tetzlaff J, Mulrow C, Gøtzsche PC, loannidis JPA, et al. The PRISMA statement for reporting systematic reviews and meta-analyses of studies that evaluate healthcare interventions: explanation and elaboration. BMJ. 2009;339(jul21 1):b2700. https://doi.org/10.1136/bmj.b2700.

14. Whelton PK, Carey RM, Aronow WS, Casey DE, Collins KJ, Himmelfarb CD, et al. 2017 ACC/AHA/AAPA/ABC/ACPM/AGS/APhA/ ASH/ASPC/NMA/PCNA guideline for the prevention, detection, evaluation, and management of high blood pressure in adults a report of the American College of Cardiology/American Heart Association Task Force on clinical practice guidelines. Hypertension. 2018; 71(6):E13-115. https//doi.org/10.1161/HYP.0000000000000065.

15. Balduzzi S, Rücker G, Schwarzer G. How to perform a meta-analysis with R: a practical tutorial. Evid Based Ment Health. 2019;22(4):153-60. https://doi. org/10.1136/ebmental-2019-300117

16. Mantel N, Haenszel W. Statistical aspects of the analysis of data from retrospective studies of disease. J Natl Cancer Inst. 1959;22(4):719-48.

17. Cochran WG. The combination of estimates from different experiments. Biometrics. 1954:10(1):101-29. https://doi.org/10.2307/3001666.

18. Higgins JPT, Thompson SG. Quantifying heterogeneity in a meta-analysis. Stat Med. 2002;21(11):1539-58. https://doi.org/10.1002/sim.1186.

19. UNAIDS. 2020 Global AIDS update: seizing the moment; tackling entrenched inequalities to end epidemics. Geneva; 2020. [cited 2020 Aug 3]. Available from: https://www.unaids.org/sites/default/files/media_asset/2020_ global-aids-report_en.pdf

20. Mills KT, Bundy JD, Kelly TN, Reed JE, Kearney PM, Reynolds K, Chen J, He J. Global disparities of hypertension prevalence and control. Circulation. 2016; 134(6):441-50. https://doi.org/10.1161/CIRCULATIONAHA.115.018912.

21. Thompson SG, Higgins JPT. How should meta-regression analyses be undertaken and interpreted? Stat Med. 2002;21(11):1559-73. https://doi. org/10.1002/sim.1187.

22. Althoff KN, Smit M, Reiss $P$, Justice AC. HIV and ageing: improving quantity and quality of life. Curr Opin HIV AIDS. 2016;11(5):527-36. https://doi.org/1 $0.1097 / \mathrm{COH} .0000000000000305$

23. Drain PK, Hong T, Hajat A, Krows M, Govere S, Thulare H, Moosa MYS, Bassett I, Celum C. Integrating hypertension screening at the time of voluntary HIV testing among adults in South Africa. PLoS One. 2019;14(2): e0210161. https://doi.org/10.1371/journal.pone.0210161.

24. Malaza A, Mossong J, Barnighausen T, Newell M-L. Hypertension and obesity in adults living in a high HIV prevalence rural area in South Africa. PLoS One. 2012;7(10):e47761. https://doi.org/10.1371/journal.pone.0047761.
25. Nduka CU, Stranges S, Sarki AM, Kimani PK, Uthman OA. Evidence of increased blood pressure and hypertension risk among people living with HIV on antiretroviral therapy: a systematic review with meta-analysis. J Hum Hypertens. 2016;30(6):355-62. https://doi.org/10.1038/jhh.2015.97.

26. Smit M, Smit C, Geerlings S, Gras L, Brinkman K, Hallett TB, de Wolf F, on behalf of the Athena Observational Cohort. Changes in first-line CART regimens and short-term clinical outcome between 1996 and 2010 in the Netherlands. PLoS One. 2013;8(9):e76071. https://doi.org/10.1371/journal. pone. 0076071.

27. Higgins JPT, Thompson SG. Controlling the risk of spurious findings from meta-regression. Stat Med. 2004;23(11):1663-82. https://doi.org/10.1002/ sim. 1752 .

28. National Heart Lung and Blood Institute. Study quality assessment tools. [cited 2019 Dec 1]. Available from: https://www.nhlbi.nih.gov/health-topics/ study-quality-assessment-tools.

29. Egger M, Smith GD, Schneider M, Minder C. Bias in meta-analysis detected by a simple, graphical test. Br Med J. 1997;315(7109):629-34. https://doi. org/10.1136/bmj.315.7109.629.

30. IntHout J, loannidis JP, Borm GF. The Hartung-Knapp-Sidik-Jonkman method for random effects meta-analysis is straightforward and considerably outperforms the standard DerSimonian-Laird method. BMC Med Res Methodol. 2014;14(1):25. https://doi.org/10.1186/1471-2288-14-25.

31. Viechtbauer W. Conducting meta-analysis in R with the metafor package. J Stat Softw. 2010;36(3):1-48.

32. Ake JA, Polyak CS, Crowell TA, et al. Noninfectious Comorbidity in the African Cohort Study (AFRICOS). Clin Infect Dis. 2018;69:639-47.

33. AkI LD, Valadares ALR, Gomes DC, Pinto-Neto AM, Costa-Paiva L. Factors associated with metabolic syndrome in middle-aged women with and without HIV. Menopause. 2016;22:1398-9.

34. Benzekri NA, Seydi M, Doye IN, Toure M, Sy MP, Kiviat NB, et al. Increasing prevalence of hypertension among HIV-positive and negative adults in Senegal, West Africa, 1994-2015. PLoS One. 2018;13(12):e0208635.

35. Bergersen BM, Sandvik L, Dunlop O, Birkeland K, Bruun JN. Prevalence of hypertension in HIV-positive patients on highly active retroviral therapy (HAART) compared with HAART-Naive and HIV-negative controls: results from a Norwegian study of 721 patients. Eur J Clin Microbiol Infect Dis. 2003;22:731-6.

36. Bonfanti P, Giannattasio C, Ricci E, Facchetti R, Rosella E, Franzetti M, Cordier L, Pusterla L, Bombelli M, Sega R, Quirino T, Mancia G. HIV and metabolic syndrome: a comparison with the general population. J Acquir Immune Defic Syndr. 2007;45(4):426-31. https:/doi.org/10.1097/QAl.0b013e318074ef83.

37. Burkhalter F, Sannon H, Mayr M, Dickenmann M, Ernst S. Prevalence and risk factors for chronic kidney disease in a rural region of Haiti. Swiss Med Wkly. 2014;144:w14067.

38. Chhabra S, Underwood J, Cole JH, et al. Clinical research cerebral MRI findings in HIV-positive subjects and appropriate controls. AIDS. 2018;32: 2077-2081.

39. Chow FC, Regan S, Feske S, Meigs JB, Grinspoon SK, Triant VA. Comparison of ischemic stroke incidence in HIV-infected and non-HIV-infected patients in a US health care system. J Acquir Immune Defic Syndr. 2012;60:351-8.

40. Clark SJ, Gomez-Olive FX, Houle B, et al. Cardiometabolic disease risk and HIV status in rural South Africa: establishing a baseline. BMC Public Health. 2015;15:135.

41. Cortes YI, Reame N, Zeana C, Jia H, Ferris DC, Shane E. Cardiovascular Risk in HIV-Infected and Uninfected Postmenopausal Minority Women: Use of the Framingham Risk Score. J Women's Heal. 2017;26:241-8.

42. Crystal HA, Weedon J, Holman S, et al. Associations of cardiovascular variables and HAART with cognition in middle-aged HIV-infected and uninfected women. J Neurovirol. 2011;17:469-76.

43. Ding $Y$, Lin H, Shen W, Wu Q, Gao M, He N. Interaction Effects between HIV and Aging on Selective Neurocognitive Impairment. J Neuroimmune Pharmacol. 2017:12:661-9.

44. Durand M, Sheehy O, Baril JG, Lelorier J, Tremblay CL. Association between HIV infection, antiretroviral therapy, and risk of acute myocardial infarction: A cohort and nested case-control study using Québec's Public Health Insurance database. J Acquir Immune Defic Syndr. 2011;57:245-53.

45. Echeverria P, Bonjoch A, Molto J, et al. Pulse wave velocity as index of arterial stiffness in HIV-infected patients compared with a healthy population. J Acquir Immune Defic Syndr. 2014;65:50-6.

46. Gallant J, Hsue PY, Shreay S, Meyer N. Comorbidities among US patients with prevalent HIV infection - a trend analysis. J Infect Dis. 2017;216:1525-33. 
47. Gelpi M, Afzal S, Lundgren J, et al. Higher risk of abdominal obesity, elevated low-density lipoprotein cholesterol, and hypertriglyceridemia, but not of hypertension, in people living with human immunodeficiency virus (HIV): results from the Copenhagen Comorbidity in HIV Infection Study. Clin Infect Dis. 2018;67:579-86.

48. Godijk NG, Vos AG, Jongen WW, et al. Heart Rate Variability, HIV and the Risk of Cardiovascular Diseases in Rural South Africa. Glob Heart. 2020;15:17.

49. Guaraldi G, Orlando G, Zona S, et al. Premature age-related comorbidities among HIV-infected persons compared with the general population. Clin Infect Dis. 2011:53:1120-6.

50. Guaraldi G, Malagoli A, Calcagno A, et al. The increasing burden and complexity of multi-morbidity and polypharmacy in geriatric HIV patients: a cross sectional study of people aged 65 - 74 years and more than 75 years. BMC Geriatr. 2018;18:99.

51. Hasse B, Tarr PE, Marques-Vidal P, et al. Strong Impact of Smoking on Multimorbidity and Cardiovascular Risk Among Human Immunodeficiency Virus-Infected Individuals in Comparison With the General Population. Open Forum Infect Dis. 2015;2:ofv108.

52. Hendriks ME, Wit FWNM, Roos MTL, et al. Hypertension in Sub-Saharan Africa: Cross-Sectional Surveys in Four Rural and Urban Communities. PLoS One. 2012;7:e32638.

53. Hopkins KL, Hlongwane K, Otwombe K, et al. Demographics and health profile on precursors of non-communicable diseases in adults testing for HIV in Soweto, South Africa: A cross-sectional study. BMJ Open. 2019;9:30701.

54. Jerico $\mathrm{C}$, Knobel $\mathrm{H}$, Montero $\mathrm{M}$, et al. Hypertension in HIV-infected patients: prevalence and related factors. Am J Hypertens. 2005;18:1396-401.

55. Kavishe B, Biraro S, Baisley K, et al. High prevalence of hypertension and of risk factors for non-communicable diseases (NCDs): a population based cross-sectional survey of NCDS and HIV infection in Northwestern Tanzania and Southern Uganda. BMC Med. 2015;13:126.

56. Kelly P, Katubulushi M, Todd J, et al. Micronutrient supplementation has limited effects on intestinal infectious disease and mortality in a Zambian population of mixed HIV status: a cluster randomized trial. Am J Clin Nutr. 2008;88:1010-7.

57. Kingery JR, Alfred $Y$, Smart LR, et al. Short-term and long-term cardiovascular risk, metabolic syndrome and HIV in Tanzania. Heart. 2016; 102:1200-5.

58. Klein DB, Leyden WA, Xu L, et al. Declining relative risk for myocardial infarction among HIV-positive compared with HIV-negative individuals with access to care. Clin Infect Dis. 2015;60:1278-80.

59. Kunisaki KM, Akgun KM, Fiellin DA, et al. Prevalence and correlates of obstructive sleep apnoea among patients with and without HIV infection. HIV Med. 2015;16:105-13.

60. Kwarisiima D, Balzer L, Heller D, et al. Population-Based Assessment of Hypertension Epidemiology and Risk Factors among HIV-Positive and General Populations in Rural Uganda. PLoS One. 2016;11:e0156309.

61. Maciel RA, Kluck HM, Durand M, Sprinz E. Comorbidity is more common and occurs earlier in persons living with HIV than in HIV-uninfected matched controls, aged 50 years and older: A cross-sectional study. Int J Infect Dis. 2018;70:30-35

62. Masyuko SJ, Page ST, Kinuthia J, et al. Metabolic syndrome and 10-year cardiovascular risk among HIV-positive and HIV-negative adults: A crosssectional study. Medicine (Baltimore). 2020;99:e20845.

63. Minami R, Takahama S, Yamamoto M. Correlates of telomere length shortening in peripheral leukocytes of HIV-infected individuals and association with leukoaraiosis. PLoS One. 2019;14:e0218996.

64. Mondy K, Overton ET, Grubb J, et al. Metabolic syndrome in HIV-infected patients from an urban, midwestern US outpatient population. Clin Infect Dis. 2007:44:726-34.

65. Monteiro P, Miranda-Filho DB, Bandeira F, et al. Is arterial stiffness in HIVinfected individuals associated with HIV-related factors? Brazilian J Med Biol Res. 2012;45:818-26.

66. Nakanga WP, Prynn JE, Banda L, et al. Prevalence of impaired renal function among rural and urban populations: findings of a cross-sectional study in Malawi. Wellcome Open Res. 2019;4.

67. Nakibuuka J, Sajatovic M, Nankabirwa J, et al. Stroke-Risk Factors Differ between Rural and Urban Communities: Population Survey in Central Uganda. Neuroepidemiology. 2015;44:156-65.

68. Odden MC, Scherzer R, Bacchetti $P$, et al. Cystatin $C$ level as a marker of kidney function in human immunodeficiency virus infection: the FRAM study. Arch Intern Med. 2007;167:2213-9.
69. Pacheco AG, Grinsztejn B, Fonseca M de JM da, et al. HIV infection is not associated with carotid intima-media thickness in Brazil: a cross-sectional analysis from the INI/ELSA-Brasil study. PLoS One. 2016;11:e0158999.

70. Rucker SCM, Tayea A, Bitilinyu-Bangoh J, et al. High rates of hypertension, diabetes, elevated low-density lipoprotein cholesterol, and cardiovascular disease risk factors in HIV-infected patients in Malawi. AIDS. 2018;32:253-60.

71. Russell E, Albert A, Côté $H$, et al. Rate of dyslipidemia higher among women living with HIV: A comparison of metabolic and cardiovascular health in a cohort to study aging in HIV. HIV Med. 2020;21:418-28.

72. Ryscavage P, Still W, Nyemba V, Stafford K. Prevalence of Systemic Hypertension Among HIV-Infected and HIV-Uninfected Young Adults in Baltimore, Maryland. South Med J. 2019;112:387-91.

73. Sanders J, Steverson A, Pawlowski A, et al. Atrial Fibrillation (AF) and Atrial Flutter (AFL) prevalence and characteristics for persons with Human Immunodeficiency Virus ( $\mathrm{HIV}+$ ) and matched uninfected controls. J Am Coll Cardiol. 2017;69:540.

74. Sarfo FS, Nichols M, Agyei B, et al. Burden of subclinical carotid atherosclerosis and vascular risk factors among people living with HIV in Ghana. J Neurol Sci. 2019;397:103-11.

75. Saves $\mathrm{M}$, Chene $\mathrm{G}$, Ducimetiere $\mathrm{P}$, et al. Risk factors for coronary heart disease in patients treated for human immunodeficiency virus infection compared with the general population. Clin Infect Dis. 2003;37:292-8.

76. Savinelli S, De Francesco D, Feeney E, et al. Factors associated with obesity in the Pharmacokinetic and Clinical Observations in People over Fifty (POPPY) cohort: an observational cross-sectional analysis. HIV Med. 2020;21: 441-52.

77. Scholten F, Mugisha J, Seeley J, et al. Health and functional status among older people with HIV/AIDS in Uganda. BMC Public Health. 2011;11:886.

78. Schutte AE, Schutte R, Huisman HW, et al. Are behavioural risk factors to be blamed for the conversion from optimal blood pressure to hypertensive status in Black South Africans? A 5-year prospective study. Int J Epidemiol. 2012:41:1114-23.

79. Touloumi G, Kalpourtzi N, Papastamopoulos V, et al. Cardiovascular risk factors in HIV infected individuals: Comparison with general adult control population in Greece. PLoS One. 2020;15.

80. Triant VA, Lee H, Hadigan C, Grinspoon SK. Increased Acute Myocardial Infarction Rates and Cardiovascular Risk Factors among Patients with Human Immunodeficiency Virus Disease. J Clin Endocrinol Metab. 2007;92: 2506-12.

81. van Heerden A, Barnabas R V, Norris SA, Micklesfield LK, van Rooyen H, Celum C. High prevalence of HIV and non-communicable disease (NCD) risk factors in rural KwaZulu-Natal, South Africa. J Int AIDS Soc. 2017:20:e25012.

82. Watson C, Busovaca E, Foley JM, et al. White matter hyperintensities correlate to cognition and fiber tract integrity in older adults with HIV. J Neurovirol. 2017;23:422-9.

83. Yang H-Y, Beymer MR, Suen S. Chronic Disease Onset Among People Living with HIV and AIDS in a Large Private Insurance Claims Dataset. Sci Rep. 2019;9:18514.

84. Yu B, Pasipanodya E, Montoya JL, et al. Metabolic Syndrome and Neurocognitive Deficits in HIV Infection. J Acquir Immune Defic Syndr. 2019; 81:95-101.

85. Xu Y, Chen X, Wang K. Global prevalence of hypertension among people living with HIV: a systematic review and meta-analysis. J Am Soc Hypertens. 2017;11(8):530-40. https://doi.org/10.1016/j.jash.2017.06.004.

86. Bigna JJ, Ndoadoumgue AL, Nansseu JR, Tochie JN, Nyaga UF, Nkeck JR, Foka AJ, Kaze AD, Noubiap JJ. Global burden of hypertension among people living with HIV in the era of increased life expectancy: a systematic review and meta-analysis. J Hypertens. 2020;38(9):1659-68. https://doi.org/1 0.1097/HJH.0000000000002446.

87. Todowede OO, Mianda SZ, Sartorius B. Prevalence of metabolic syndrome among HIV-positive and HIV-negative populations in sub-Saharan Africa - a systematic review and meta-analysis. Syst Rev. 2019;8(1):4. https://doi.org/1 0.1186/s13643-018-0927-y.

88. van Zoest RA, van der Valk M, Wit FW, Vaartjes I, Kooij KW, Hovius JW, Prins M, Reiss P, AGEhIV Cohort Study Group. Suboptimal primary and secondary cardiovascular disease prevention in HIV-positive individuals on antiretroviral therapy. Eur J Prev Cardiol. 2017;24(12):1297-307. https://doi.org/10.1177/2 047487317714350

89. Hajjar I, Kotchen JM, Kotchen TA. Hypertension: trends in prevalence, incidence, and control. Annu Rev Public Health. 2006;27(1):465-90. https:// doi.org/10.1146/annurev.publhealth.27.021405.102132. 
90. Kibachio J, Mwenda V, Ombiro O, Kamano JH, Perez-Guzman PN, Mutai KK, et al. Recommendations for the use of mathematical modelling to support decision-making on integration of non-communicable diseases into HIV care. J Int AIDS Soc. 2020;23(S1):238-361.

91. Manne-Goehler J, Montana L, Gomez-Olive FX, Rohr J, Harling G, Wagner RG, et al. The ART advantage: health care utilization for diabetes and hypertension in rural South Africa. J Acquir Immune Defic Syndr. 2017;75(5): 561-7. https://doi.org/10.1097/QAl.0000000000001445.

92. Reniers G, Wamukoya M, Urassa M, Nyaguara A, Nakiyingi-Miiro J, Lutalo T, Hosegood V, Gregson S, Gómez-Olivé X, Geubbels E, Crampin AC, Wringe A, Waswa L, Tollman S, Todd J, Slaymaker E, Serwadda D, Price A, Oti S,

Nyirenda MJ, Nabukalu D, Nyamukapa C, Nalugoda F, Mugurungi O, Mtenga B, Mills L, Michael D, McLean E, McGrath N, Martin E, Marston M, Maquins S, Levira F, Kyobutungi C, Kwaro D, Kasamba I, Kanjala C, Kahn K, Kabudula C, Herbst K, Gareta D, Eaton JW, Clark SJ, Church K, Chihana M, Calvert C, Beguy D, Asiki G, Amri S, Abdul R, Zaba B. Data resource profile: network for analysing longitudinal population-based HIV/AIDS data on Africa (ALPHA Network). Int J Epidemiol. 2016;45(1):83-93. https://doi.org/10.1093/ije/ dyv343.

93. Mudie K, Mei Jin Tan M, Kendall L, Addo J, dos-Santos-Silva I, Quint J, et al. Non-communicable diseases in sub-saharan Africa: a scoping review of large cohort studies. J Glob Health. 2019:9(2):020409.

94. Forman JP, Stampfer MJ, Curhan GC. Diet and lifestyle risk factors associated with incident hypertension in women. JAMA. 2009;302(4):401-11. https:// doi.org/10.1001/jama.2009.1060.

\section{Publisher's Note}

Springer Nature remains neutral with regard to jurisdictional claims in published maps and institutional affiliations.

Ready to submit your research? Choose BMC and benefit from:

- fast, convenient online submission

- thorough peer review by experienced researchers in your field

- rapid publication on acceptance

- support for research data, including large and complex data types

- gold Open Access which fosters wider collaboration and increased citations

- maximum visibility for your research: over $100 \mathrm{M}$ website views per year

At BMC, research is always in progress.

Learn more biomedcentral.com/submissions 